une revue Gallia

Rhône-Alpes | 2008

\title{
Davezieux
}

(Davezieux Peaugres Saint-Claire) RD 82, RD 820

\section{Frédéric Cordier}

\section{(2) OpenEdition \\ 1 Journals}

Édition électronique

URL : http://journals.openedition.org/adlfi/1519

ISSN : 2114-0502

Éditeur

Ministère de la culture

Référence électronique

Frédéric Cordier, "Davezieux », ADLFI. Archéologie de la France - Informations [En ligne], Rhône-Alpes, mis en ligne le 01 mars 2008, consulté le 24 avril 2019. URL : http://journals.openedition.org/ adlfi/1519

Ce document a été généré automatiquement le 24 avril 2019

(C) Ministère de la Culture et de la Communication, CNRS 


\section{Davezieux}

(Davezieux Peaugres Saint-Claire) RD 82, RD 820

\section{Frédéric Cordier}

Identifiant de l'opération archéologique : 9732 et 9786

Date de l'opération : 2008 (EX)

1 Deux séries de fossés et/ou de drains ont été relevées à l'extrémité sud-est et dans la partie centrale du tracé. L'une se situe sur un replat, au bas des pentes du bois de Gourdan, l'autre plus à l'est, à mi-pente dans le vallon des Combes. Elles n'ont livré aucun mobilier qui permette un calage chronologique précis. Leur position stratigraphique, la présence de briques ou de tuiles dans certaines d'entre elles et un mode de remplissage commun incitent toutefois à les rattacher à une période historique au sens large, peutêtre l'Antiquité en raison de la forte présence humaine connue sur ce territoire durant cette période.

2 Au lieu-dit Chamareille, une sédimentation plus importante a pu être observée en deux secteurs, sur de légers replats qui ont favorisé une meilleure conservation de vestiges de la fin de l'âge du Bronze et du début de l'âge du Fer.

3 Le premier a livré une grande fosse contenant une série céramique très homogène attribuée au Hallstatt C, ainsi que quelques éléments de mouture. Cette fosse, profonde d'une quarantaine de centimètres, s'inscrit dans un contexte sédimentaire limonoargileux gris-orange et perfore à sa base un niveau très argileux correspondant vraisemblablement à une zone de stagnation d'eau (?). La typologie des récipients (vases tonneau, jattes et jarres) permet de lui attribuer une fonction domestique. Dans ce secteur a également été observé un niveau limono-argileux brun-vert contenant de nombreux charbons de bois et des fragments de céramiques (niveau d'occupation ou de circulation ?) ainsi qu'un amas de céramique rattaché également au Hallstatt $C$.

4 Un peu plus au nord, le second secteur a livré deux structures de combustion et deux fonds de fosses. L'ensemble, profond de 0,45 $\mathrm{m}$, est creusé dans un contexte limonosableux beige et entame à sa base le socle granitique. Les structures de combustion 
correspondent à des fosses pour une cuisson à l'étouffée. Le mobilier céramique recueilli dans l'une d'elles permet de les rattacher à une phase de transition entre l'âge du Bronze et l'âge du Fer.

5 Au lieu-dit Cheval sud a été mis au jour sur un replat, à $446 \mathrm{~m}$ d'altitude, un alignement de cinq autres fosses rectangulaires de cuisson à l'étouffée attribuées à l'âge du Bronze final. Aucun niveau d'occupation n'a pu leur être associé, mais il n'est toutefois pas exclu que certains aménagements puissent exister à la surface du socle granitique.

6 A proximité, la présence de quelques tessons inclus dans une couche très charbonneuse pourrait appartenir à un niveau de circulation rattachable à une période de la Protohistoire. L'absence d'éléments typologiques dans la série céramique ne permet cependant pas d'affiner cette attribution chronologique.

\section{INDEX}

operation Expertise (EX)

Index chronologique : âge du Bronze, âge du Fer, Hallstatt

Thèmes : brique, céramique du Hallstatt, fosse, fossé, tuile

Index géographique : Rhône-Alpes, Ain (01)

\section{AUTEUR}

FRÉDÉRIC CORDIER

INRAP 